\title{
Some Fixed Point Theorems for Prešić-Hardy-Rogers Type Contractions in Metric Spaces
}

\author{
Satish Shukla, ${ }^{1}$ Stojan Radenović, ${ }^{2}$ and Slaviša Pantelic ${ }^{2}$ \\ ${ }^{1}$ Department of Applied Mathematics, Shri Vaishnav Institute of Technology and Science, Gram Baroli, Sanwer Road, \\ Indore 453331, India \\ ${ }^{2}$ Faculty of Mechanical Engineering, University of Belgrade, Kraljice Marije 16, 11120 Beograd, Serbia
}

Correspondence should be addressed to Satish Shukla; satishmathematics@yahoo.co.in

Received 2 January 2013; Accepted 7 February 2013

Academic Editor: NanJing Huang

Copyright (C) 2013 Satish Shukla et al. This is an open access article distributed under the Creative Commons Attribution License, which permits unrestricted use, distribution, and reproduction in any medium, provided the original work is properly cited.

We introduce some generalizations of Prešić type contractions and establish some fixed point theorems for mappings satisfying Prešić-Hardy-Rogers type contractive conditions in metric spaces. Our results generalize and extend several known results in metric spaces. Some examples are included which illustrate the cases when new results can be applied while old ones cannot.

\section{Introduction}

The well-known Banach contraction mapping principle states that if $(X, d)$ is a complete metric space and $T: X \rightarrow X$ is a self-mapping such that

$$
d(T x, T y) \leq \lambda d(x, y)
$$

for all $x, y \in X$, where $0 \leq \lambda<1$, then there exists a unique $x \in X$ such that $T x=x$. This point $x$ is called the fixed point of mapping $T$.

On the other hand, for mappings $T: X \rightarrow X$, Kannan [1] introduced the contractive condition:

$$
d(T x, T y) \leq \lambda[d(x, T x)+d(y, T y)],
$$

for all $x, y \in X$, where $\lambda \in[0,1 / 2)$ is a constant and proved a fixed point theorem using (2) instead of (1). The conditions (1) and (2) are independent, as it was shown by two examples in [2].

Reich [3], for mappings $T: X \rightarrow X$, generalized Banach and Kannan fixed point theorems, using contractive condition:

$$
d(T x, T y) \leq \alpha d(x, y)+\beta d(x, T x)+\gamma d(y, T y),
$$

for all $x, y \in X$, where $\alpha, \beta, \gamma$ are nonnegative constants with $\alpha+\beta+\gamma<1$. An example in [3] shows that the condition (3) is a proper generalization of (1) and (2).
For mapping $T: X \rightarrow X$ Chatterjea [4] introduced the contractive condition:

$$
d(T x, T y) \leq \lambda[d(x, T y)+d(y, T x)]
$$

for all $x, y \in X$, where $\lambda \in[0,1 / 2)$ is a constant and proved a fixed point result using (4).

Ćirić [5], for mappings $T: X \rightarrow X$, generalized all above mappings, using contractive condition:

$$
\begin{aligned}
d(T x, T y) \leq & \alpha d(x, y)+\beta d(x, T x)+\gamma d(y, T y) \\
& +\delta[d(x, T y)+d(y, T x)],
\end{aligned}
$$

for all $x, y \in X$, where $\alpha, \beta, \gamma, \delta$ are nonnegative constants with $\alpha+\beta+\gamma+2 \delta<1$. A mapping satisfying (5) is called Generalized contraction.

Hardy and Rogers [6], for mappings $T: X \rightarrow X$, used the contractive condition:

$$
\begin{aligned}
d(T x, T y) \leq & \alpha d(x, y)+\beta d(x, T x)+\gamma d(y, T y) \\
& +\delta d(x, T y)+\mu d(y, T x),
\end{aligned}
$$

for all $x, y \in X$, where $\alpha, \beta, \gamma, \delta, \mu$ are nonnegative constants with $\alpha+\beta+\gamma+\delta+\mu<1$ and proved fixed point result. Note that condition (6) generalizes all the previous conditions. 
In 1965, Prešić [7, 8] extended Banach contraction mapping principle to mappings defined on product spaces and proved the following theorem.

Theorem 1. Let $(X, d)$ be a complete metric space, $k$ a positive integer, and $f: X^{k} \rightarrow X$ a mapping satisfying the following contractive type condition:

$$
\begin{aligned}
& d\left(f\left(x_{1}, x_{2}, \ldots, x_{k}\right), f\left(x_{2}, x_{3}, \ldots, x_{k+1}\right)\right) \\
& \leq \sum_{i=1}^{k} q_{i} d\left(x_{i}, x_{i+1}\right),
\end{aligned}
$$

for every $x_{1}, x_{2}, \ldots, x_{k+1} \in X$, where $q_{1}, q_{2}, \ldots, q_{k}$ are nonnegative constants such that $q_{1}+q_{2}+\cdots+q_{k}<1$. Then there exists a unique point $x \in X$ such that $f(x, x, \ldots, x)=x$. Moreover if $x_{1}, x_{2}, \ldots, x_{k}$ are arbitrary points in $X$ and for $n \in \mathbb{N}$,

$$
x_{n+k}=f\left(x_{n}, x_{n+1}, \ldots, x_{n+k-1}\right) \text {, }
$$

then the sequence $\left\{x_{n}\right\}$ is convergent and $\lim x_{n}=f\left(\lim x_{n}\right.$, $\left.\lim x_{n}, \ldots, \lim x_{n}\right)$.

Note that condition (7) in the case $k=1$ reduces to the well-known Banach contraction mapping principle. So, Theorem 1 is a generalization of the Banach fixed point theorem. Some generalizations and applications of Prešić theorem can be seen in [9-18].

The $k$-step iterative sequence given by (8) represents a nonlinear difference equation and the solution of this equation can be assumed to be a fixed point of $f$; that is, solution of (8) is a point $x^{*} \in X$ such that $x^{*}=f\left(x^{*}, x^{*}, \ldots, x^{*}\right)$. The Prešic theorem insures the convergence of the sequence $\left\{x_{n}\right\}$ defined by (8) and provides a sufficient condition for the existence of solution of (8) in the case when mapping $f$ satisfies the condition (7). A condition, independent from (7); namely, the Prešić-Kannan condition, is considered in [11] (for the proof of independency of these conditions in case $k=1$, we refer $[1,2])$. In this paper, we introduce some generalizations of Prešić type contractions in metric spaces and use a more general condition; namely, the Prešić-HardyRogers type condition, to prove the existence of fixed point of $f$ in metric spaces. We note that this condition generalizes the result of Prešić [7, 8], Păcurar [11], Hardy and Rogers [6], and several known results in metric spaces. Some examples are included which illustrate the cases when new results can be applied while old ones cannot.

\section{Some Generalizations of Presić Type Contractions}

In this section, we introduced some Prešić type contractions in metric spaces.

Let $(X, d)$ be a metric space, $k$ a positive integer, and $f$ : $X^{k} \rightarrow X$ be a mapping.

(i) $f$ is said to be a Prešić contraction if $f$ satisfies the condition (7). (ii) $f$ is said to be a Prešić-Kannan contraction (see [11] for detail) if $f$ satisfies following condition:

$$
\begin{gathered}
d\left(f\left(x_{1}, x_{2}, \ldots, x_{k}\right), f\left(x_{2}, x_{3}, \ldots, x_{k+1}\right)\right) \\
\leq \beta \sum_{i=1}^{k+1} d\left(x_{i}, f\left(x_{i}, x_{i}, \ldots, x_{i}\right)\right)
\end{gathered}
$$

for all $x_{1}, x_{2}, \ldots, x_{k}, x_{k+1} \in X$, where

$$
0 \leq \beta k(k+1)<1 .
$$

(iii) $f$ is said to be a Prešić-Reich contraction if $f$ satisfies following condition:

$$
\begin{aligned}
& d\left(f\left(x_{1}, x_{2}, \ldots, x_{k}\right), f\left(x_{2}, x_{3}, \ldots, x_{k+1}\right)\right) \\
& \leq \sum_{i=1}^{k} \alpha_{i} d\left(x_{i}, x_{i+1}\right) \\
& \quad+\sum_{i=1}^{k+1} \beta_{i} d\left(x_{i}, f\left(x_{i}, x_{i}, \ldots, x_{i}\right)\right)
\end{aligned}
$$

for all $x_{1}, x_{2}, \ldots, x_{k}, x_{k+1} \in X$, where $\alpha_{i}, \beta_{i}$ are nonnegative constants such that

$$
\sum_{i=1}^{k} \alpha_{i}+k \sum_{i=1}^{k+1} \beta_{i}<1
$$

(iv) $f$ is said to be a Prešić-Chatterjea contraction if $f$ satisfies following condition:

$$
\begin{array}{r}
d\left(f\left(x_{1}, x_{2}, \ldots, x_{k}\right), f\left(x_{2}, x_{3}, \ldots, x_{k+1}\right)\right) \\
\leq \gamma \sum_{i=1, i \neq j}^{k+1} \sum_{j=1}^{k+1} d\left(x_{i}, f\left(x_{j}, x_{j}, \ldots, x_{j}\right)\right)
\end{array}
$$

for all $x_{1}, x_{2}, \ldots, x_{k}, x_{k+1} \in X$, where

$$
0 \leq \gamma k^{2}(k+1)<1 .
$$

(v) $f$ is said to be a Generalized-Prešić contraction if $f$ satisfies following condition:

$$
\begin{aligned}
& d\left(f\left(x_{1}, x_{2}, \ldots, x_{k}\right), f\left(x_{2}, x_{3}, \ldots, x_{k+1}\right)\right) \\
& \leq \sum_{i=1}^{k} \alpha_{i} d\left(x_{i}, x_{i+1}\right) \\
& \quad+\sum_{i=1}^{k+1} \beta_{i} d\left(x_{i}, f\left(x_{i}, x_{i}, \ldots, x_{i}\right)\right) \\
& +\beta \sum_{i=1, i \neq j}^{k+1} \sum_{j=1}^{k+1} d\left(x_{i}, f\left(x_{j}, x_{j}, \ldots, x_{j}\right)\right)
\end{aligned}
$$


for all $x_{1}, x_{2}, \ldots, x_{k}, x_{k+1} \in X$, where $\alpha_{i}, \beta_{i}, \beta$ are nonnegative constants such that

$$
\sum_{i=1}^{k} \alpha_{i}+k \sum_{i=1}^{k+1} \beta_{i}+\beta k^{2}(k+1)<1 .
$$

(vi) $f$ is said to be a Prešić-Hardy-Rogers contraction if $f$ satisfies following condition:

$$
\begin{aligned}
d\left(f\left(x_{1}, x_{2}, \ldots, x_{k}\right), f\left(x_{2}, x_{3}, \ldots, x_{k+1}\right)\right) \\
\leq \sum_{i=1}^{k} \alpha_{i} d\left(x_{i}, x_{i+1}\right) \\
\quad+\sum_{i=1}^{k+1} \sum_{j=1}^{k+1} \beta_{i, j} d\left(x_{i}, f\left(x_{j}, x_{j}, \ldots, x_{j}\right)\right)
\end{aligned}
$$

for all $x_{1}, x_{2}, \ldots, x_{k}, x_{k+1} \in X$, where $\alpha_{i}, \beta_{i, j}$ are nonnegative constants such that

$$
\sum_{i=1}^{k} \alpha_{i}+k \sum_{i=1}^{k+1} \sum_{j=1}^{k+1} \beta_{i, j}<1 .
$$

Remark 2. Note that for $\beta_{i, j}=\beta$ for all $i, j \in\{1,2, \ldots, k, k+1\}$ with $i \neq j$ and $\beta_{i, i}=\beta_{i}$ for all $i \in\{1,2, \ldots, k, k+1\}$, the PrešićHardy-Rogers contraction reduces into the GeneralizedPrešić contraction. With $\beta=0$, the Generalized-Prešić contraction reduces into the Prešić-Reich contraction and with $\alpha_{i}=0$ for all $i \in\{1,2, \ldots, k\}, \beta_{i}=0$ for all $i \epsilon$ $\{1,2, \ldots, k, k+1\}$, and $\beta=\gamma$, the Generalized-Prešić contraction reduces into the Prešić-Chatterjea contraction. With $\alpha_{i}=0$ for all $i \in\{1,2, \ldots, k\}$, the Prešić-Reich contraction reduces into the Prešić-Kannan contraction and with $\beta_{i}=0$ for all $i \in\{1,2, \ldots, k, k+1\}$, the Prešić-Reich contraction reduces into the Prešić contraction. Therefore among all above definitions, the Prešić-Hardy-Rogers contraction is the most general contraction.

Remark 3. It is easy to see that for $k=1$, Prešić-HardyRogers contraction reduces into Hardy-Rogers contraction and for $k=1$, Generalized-Prešić contraction reduces into Generalized contraction and so forth; therefore, the comparison as considered in [19] shows that the above generalization is proper.

Now, we shall prove some fixed point results for PrešićHardy-Rogers type contractions in metric spaces.

\section{Main Results}

The following theorem is the fixed point result for PrešićHardy-Rogers type contractions and the main result of this paper.

Theorem 4. Let $(X, d)$ be any complete metric space, $k$ a positive integer. Let $f: X^{k} \rightarrow X$ be a Prešić-Hardy-Rogers contraction, then $f$ has a unique fixed point in $X$.
Proof. Let $x_{0} \in X$ be arbitrary. Define a sequence $\left\{x_{n}\right\}$ in $X$ by

$$
x_{n+1}=f\left(x_{n}, \ldots, x_{n}\right), \quad n \geq 0 .
$$

If $x_{n}=x_{n+1}$ for any $n$ then $x_{n}$ is a fixed point of $f$. Therefore we assume $x_{n} \neq x_{n+1}$ for all $n$. $X$.

We shall show that this sequence is a Cauchy sequence in

For simplicity, set

$$
d_{i}=d\left(x_{i}, x_{i+1}\right), \quad D_{i, j}=d\left(x_{i}, f\left(x_{j}, \ldots, x_{j}\right)\right)
$$

$$
\forall i, j \geq 1 \text {. }
$$

For any $n \geq 0$, we obtain

$$
\begin{aligned}
d_{n+1} & \\
= & d\left(x_{n+1}, x_{n+2}\right) \\
= & d\left(f\left(x_{n}, \ldots, x_{n}\right), f\left(x_{n+1}, \ldots, x_{n+1}\right)\right) \\
\leq & d\left(f\left(x_{n}, \ldots, x_{n}\right), f\left(x_{n}, \ldots, x_{n}, x_{n+1}\right)\right) \\
& +d\left(f\left(x_{n}, \ldots, x_{n}, x_{n+1}\right), f\left(x_{n}, \ldots, x_{n}, x_{n+1}, x_{n+1}\right)\right) \\
& +\cdots+d\left(f\left(x_{n}, x_{n+1}, \ldots, x_{n+1}\right), f\left(x_{n+1}, \ldots, x_{n+1}\right)\right),
\end{aligned}
$$

using (17), it follows from above inequality that

$$
\begin{aligned}
& d_{n+1} \leq\left\{\alpha_{k} d_{n}+\left[\sum_{j=1}^{k} \beta_{1, j}+\sum_{j=1}^{k} \beta_{2, j}+\cdots+\sum_{j=1}^{k} \beta_{k, j}\right] D_{n, n}\right. \\
& +\left[\sum_{i=1}^{k} \beta_{i, k+1}\right] D_{n, n+1}+\left[\sum_{j=1}^{k} \beta_{k+1, j}\right] D_{n+1, n} \\
& \left.+\beta_{k+1, k+1} D_{n+1, n+1}\right\} \\
& +\left\{\alpha_{k-1} d_{n}\right. \\
& +\left[\sum_{j=1}^{k-1} \beta_{1, j}+\sum_{j=1}^{k-1} \beta_{2, j}+\cdots+\sum_{j=1}^{k-1} \beta_{k-1, j}\right] D_{n, n} \\
& +\left[\sum_{i=1}^{k-1} \beta_{i, k}+\sum_{i=1}^{k-1} \beta_{i, k+1}\right] D_{n, n+1} \\
& +\left[\sum_{j=1}^{k-1} \beta_{k, j}+\sum_{j=1}^{k-1} \beta_{k+1, j}\right] D_{n+1, n} \\
& \left.+\left[\sum_{j=k}^{k+1} \beta_{k, j}+\sum_{j=k}^{k+1} \beta_{k+1, j}\right] D_{n+1, n+1}\right\} \\
& +\cdots
\end{aligned}
$$




$$
\begin{aligned}
& +\left\{\alpha_{1} d_{n}+\beta_{1,1} D_{n, n}\right. \\
& +\left[\sum_{j=2}^{k+1} \beta_{1, j}\right] D_{n, n+1}+\left[\sum_{i=2}^{k+1} \beta_{i, 1}\right] D_{n+1, n} \\
& \left.+\left[\sum_{j=2}^{k+1} \beta_{2, j}+\sum_{j=2}^{k+1} \beta_{3, j}+\cdots+\sum_{j=2}^{k+1} \beta_{k+1, j}\right] D_{n+1, n+1}\right\},
\end{aligned}
$$

that is,

$$
\begin{aligned}
d_{n+1} \leq & {\left[\sum_{i=1}^{k} \alpha_{i}\right] d_{n} } \\
+ & \left\{\left[\sum_{i=1}^{k} \sum_{j=1}^{k} \beta_{i, j}\right] D_{n, n}+\left[\sum_{i=1}^{k} \beta_{i, k+1}\right] D_{n, n+1}\right. \\
& \left.+\left[\sum_{j=1}^{k} \beta_{k+1, j}\right] D_{n+1, n}+\beta_{k+1, k+1} D_{n+1, n+1}\right\} \\
+ & \left\{\left[\sum_{i=1}^{k-1} \sum_{j=1}^{k-1} \beta_{i, j}\right] D_{n, n}+\left[\sum_{i=1}^{k-1} \sum_{j=k}^{k+1} \beta_{i, j}\right] D_{n, n+1}\right. \\
+ & \left.+\left[\sum_{i=k}^{k+1 k-1} \sum_{j=1} \beta_{i, j}\right] D_{n+1, n}+\left[\sum_{i=k}^{k} \sum_{j=k}^{k+1} \beta_{i, j}\right] D_{n+1, n+1}\right\} \\
+ & \left\{\beta_{1,1} D_{n, n}+\left[\sum_{j=2}^{k+1} \beta_{1, j}\right] D_{n, n+1}\right. \\
& \left.+\left[\sum_{i=2}^{k+1} \beta_{i, 1}\right] D_{n+1, n}+\left[\sum_{i=2}^{k+1} \sum_{j=2}^{k+1} \beta_{i, j}\right] D_{n+1, n+1}\right\}
\end{aligned}
$$

that is,

$$
\begin{aligned}
& d_{n+1} \\
& \leq\left[\sum_{i=1}^{k} \alpha_{i}\right] d_{n} \\
& +\left[\sum_{i=1}^{k} \sum_{j=1}^{k} \beta_{i, j}+\sum_{i=1}^{k-1} \sum_{j=1}^{k-1} \beta_{i, j}+\cdots+\sum_{i=1}^{2} \sum_{j=1}^{2} \beta_{i, j}+\beta_{1,1}\right] D_{n, n} \\
& +\left[\sum_{i=1}^{k} \beta_{i, k+1}+\sum_{i=1}^{k-1 k+1} \sum_{j=k} \beta_{i, j}+\cdots+\sum_{i=1}^{2} \sum_{j=3}^{k+1} \beta_{i, j}+\sum_{j=2}^{k+1} \beta_{1, j}\right] D_{n, n+1} \\
& +\left[\sum_{j=1}^{k} \beta_{k+1, j}+\sum_{i=k}^{k+1 k-1} \sum_{j=1} \beta_{i, j}+\cdots+\sum_{i=3}^{k+1} \sum_{j=1}^{2} \beta_{i, j}+\sum_{i=2}^{k+1} \beta_{i, 1}\right] D_{n+1, n}
\end{aligned}
$$

$$
\begin{aligned}
& +\left[\sum_{i=2}^{k+1 k+1} \sum_{j=2} \beta_{i, j}+\sum_{i=3}^{k+1 k+1} \sum_{j=3} \beta_{i, j}+\cdots+\sum_{i=k}^{k+1 k+1} \sum_{j=k} \beta_{i, j}+\beta_{k+1, k+1}\right] D_{n+1, n+1} \\
= & A d_{n}+B D_{n, n}+C D_{n, n+1}+E D_{n+1, n}+F D_{n+1, n+1},
\end{aligned}
$$

where $A, B, C, E$, and $F$ are the coefficients of $d_{n}, D_{n, n}, D_{n, n+1}$, $D_{n+1, n}$, and $D_{n+1, n+1}$, respectively, in the above inequality.

By definition, $D_{n, n}=d\left(x_{n}, f\left(x_{n}, \ldots, x_{n}\right)\right)=d\left(x_{n}, x_{n+1}\right)=$ $d_{n}, D_{n, n+1}=d\left(x_{n}, f\left(x_{n+1}, \ldots, x_{n+1}\right)\right)=d\left(x_{n}, x_{n+2}\right)$, $D_{n+1, n}=d\left(x_{n+1}, f\left(x_{n}, \ldots, x_{n}\right)\right)=d\left(x_{n+1}, x_{n+1}\right)=0$, $D_{n+1, n+1}=d\left(x_{n+1}, f\left(x_{n+1}, \ldots, x_{n+1}\right)\right)=d\left(x_{n+1}, x_{n+2}\right)=d_{n+1}$, therefore

$$
\begin{aligned}
d_{n+1} & \leq A d_{n}+B d_{n}+C d\left(x_{n}, x_{n+2}\right)+F d_{n+1} \\
& \leq A d_{n}+B d_{n}+C d\left(x_{n}, x_{n+1}\right)+C d\left(x_{n+1}, x_{n+2}\right)+F d_{n+1} \\
& =(A+B+C) d_{n}+(C+F) d_{n+1},
\end{aligned}
$$

that is,

$$
(1-C-F) d_{n+1} \leq(A+B+C) d_{n} .
$$

Again, as $d_{n+1}=d\left(x_{n}, x_{n+1}\right)=d\left(x_{n+1}, x_{n}\right)$, interchanging the role of $x_{n}$ and $x_{n+1}$, and repeating above process, we obtain

$$
(1-E-B) d_{n+1} \leq(A+F+E) d_{n} .
$$

It follows from (26) and (27) that

$$
\begin{aligned}
(2-B-C-E-F) d_{n+1} & \leq(2 A+B+C+E+F) d_{n}, \\
d_{n+1} & \leq \frac{2 A+B+C+E+F}{2-B-C-E-F} d_{n}, \\
d_{n+1} & \leq \lambda d_{n},
\end{aligned}
$$

where $\lambda=(2 A+B+C+E+F) /(2-B-C-E-F)$.

Using (18), we obtain

$$
\begin{aligned}
A+B+ & C+E+F \\
= & \sum_{i=1}^{k} \alpha_{i}+\sum_{i=1}^{k} \sum_{j=1}^{k} \beta_{i, j}+\sum_{i=1}^{k-1} \sum_{j=1}^{k-1} \beta_{i, j}+\cdots+\sum_{i=1}^{2} \sum_{j=1}^{2} \beta_{i, j}+\beta_{1,1} \\
& +\sum_{i=1}^{k} \beta_{i, k+1}+\sum_{i=1}^{k-1} \sum_{j=k}^{k+1} \beta_{i, j}+\cdots+\sum_{i=1}^{2} \sum_{j=3}^{k+1} \beta_{i, j}+\sum_{j=2}^{k+1} \beta_{1, j} \\
& +\sum_{j=1}^{k} \beta_{k+1, j}+\sum_{i=k}^{k+1} \sum_{j=1}^{k-1} \beta_{i, j}+\cdots+\sum_{i=3}^{k+1} \sum_{j=1}^{2} \beta_{i, j}+\sum_{i=2}^{k+1} \beta_{i, 1} \\
& +\sum_{i=2}^{k+1} \sum_{j=2}^{k+1} \beta_{i, j}+\sum_{i=3}^{k+1} \sum_{j=3}^{k+1} \beta_{i, j}+\cdots+\sum_{i=k}^{k+1} \sum_{j=k}^{k+1} \beta_{i, j}+\beta_{k+1, k+1} \\
= & \sum_{i=1}^{k} \alpha_{i}+k \sum_{i=1}^{k+1} \sum_{j=1}^{k+1} \beta_{i, j} \\
< & 1 .
\end{aligned}
$$


So $0 \leq \lambda<1$. By (28), we obtain

$$
d_{n+1} \leq \lambda^{n+1} d_{0} \quad \forall n \geq 0 .
$$

Suppose $n, m \in \mathbb{N}$ with $m>n$. Then

$$
\begin{aligned}
d\left(x_{n}, x_{m}\right) & \\
& \leq d\left(x_{n}, x_{n+1}\right)+d\left(x_{n+1}, x_{n+2}\right)+\cdots+d\left(x_{m-1}, x_{m}\right) \\
& =d_{n}+d_{n+1}+\cdots+d_{m-1} \\
& \leq \lambda^{n} d_{0}+\lambda^{n+1} d_{0}+\cdots+\lambda^{m-1} d_{0} \\
& \leq \frac{\lambda^{n}}{1-\lambda} d_{0}
\end{aligned}
$$

as $0 \leq \lambda<1$, it follows from the above inequality that $\lim _{n \rightarrow \infty} d\left(x_{n}, x_{m}\right)=0$. Therefore $\left\{x_{n}\right\}$ is a Cauchy sequence. By completeness of $X$, there exists $u \in X$ such that $\lim _{n \rightarrow \infty} x_{n}=u$.

We shall show that $u$ is the fixed point of $f$. Note that

$$
\begin{aligned}
& d(u, f(u, \ldots, u)) \\
& \quad \leq d\left(u, x_{n+1}\right)+d\left(x_{n+1}, f(u, \ldots, u)\right) \\
& \quad=d\left(u, x_{n+1}\right)+d\left(f\left(x_{n}, \ldots, x_{n}\right), f(u, \ldots, u)\right),
\end{aligned}
$$

using a similar process as used in the calculation of $d_{n+1}$, we obtain

$$
\begin{aligned}
d(u, f( & (u, \ldots, u)) \\
\leq & d\left(u, x_{n+1}\right)+A d\left(x_{n}, u\right)+B d\left(x_{n}, f\left(x_{n}, \ldots, x_{n}\right)\right) \\
& +C d\left(x_{n}, f(u, \ldots, u)\right)+E d\left(u, f\left(x_{n}, \ldots, x_{n}\right)\right) \\
& +F d(u, f(u, \ldots, u)) \\
\leq & d\left(u, x_{n+1}\right)+A d\left(x_{n}, u\right)+B d\left(x_{n}, x_{n+1}\right)+C d\left(x_{n}, u\right) \\
& +C d(u, f(u, \ldots, u))+E d\left(u, x_{n+1}\right) \\
& +F d(u, f(u, \ldots, u)),
\end{aligned}
$$

that is,

$$
\begin{aligned}
& d(u, f(u, \ldots, u)) \\
& \quad \leq \frac{A+B+C}{1-C-F} d\left(x_{n}, u\right)+\frac{1+B+E}{1-C-F} d\left(x_{n+1}, u\right) .
\end{aligned}
$$

Using the fact that $\lim _{n \rightarrow \infty} x_{n}=u$, it follows from the above inequality that

$$
d(u, f(u, \ldots, u))=0 \text { that is, } f(u, \ldots, u)=u \text {. }
$$

Thus $u$ is a fixed point of $f$. For uniqueness, let $v$ be another fixed point of $f$, that is, $f(v, \ldots, v)=v$. Again using a similar process as used in the calculation of $d_{n+1}$, we obtain

$$
\begin{aligned}
d(u, v) \leq & A d(u, v)+B d(u, f(u, \ldots, u)) \\
& +C d(u, f(v, \ldots, v))+E d(v, f(u, \ldots, u)) \\
& +F d(v, f(v, \ldots, v)) \\
= & (A+C+E) d(u, v),
\end{aligned}
$$

as $A+B+C+E+F<1$, we obtain $d(u, v)=0$, that is, $u=v$. Thus fixed point is unique.

Remark 5. For $k=1$ in the above theorem, we obtain the result of Hardy and Rogers [6]. For $\beta_{i, j}=0$ for all $i, j \in$ $\{1,2, \ldots, k, k+1\}$, we obtain the fixed point result of Prešić. Therefore, above theorem is a generalization of the results of Hardy and Rogers and Prešić.

With Remark 2, the following corollaries are obtained.

Corollary 6. Let $(X, d)$ be any complete metric space, $k a$ positive integer, and $f: X^{k} \rightarrow X$ a Generalized Prešić contraction. Then $f$ has a unique fixed point in $X$.

For $k=1$ in above corollary, we obtain the fixed point result of Ćirić [5].

Corollary 7. Let $(X, d)$ be any complete metric space, $k a$ positive integer, and $f: X^{k} \rightarrow X$ a Prešić-Reich contraction. Then $f$ has a unique fixed point in $X$.

For $k=1$ in the above corollary, we obtain the fixed point result of Reich [3].

Corollary 8. Let $(X, d)$ be any complete metric space, $k a$ positive integer, and $f: X^{k} \rightarrow X$ a Prešić-Kannan contraction. Then $f$ has a unique fixed point in $X$.

For $k=1$ in above the corollary, we obtain the fixed point result of Kannan [2].

Corollary 9. Let $(X, d)$ be any complete metric space, $k$ a positive integer, and $f: X^{k} \rightarrow X$ a Prešić-Chatterjea contraction. Then $f$ has a unique fixed point in $X$.

For $k=1$ in above corollary, we obtain the fixed point result of Chatterjea [4].

The following are some examples which illustrate the cases when known results are not applicable, while our new results can be used to conclude the existence of fixed point of mapping. 
Example 10. Let $X=[0,1]$ with usual metric. For $k=2$ define $f: X^{2} \rightarrow X$ by

$$
f(x, y)= \begin{cases}\frac{1}{5}, & \text { if } x=y=1 \\ \frac{x+y}{5}, & \text { otherwise. }\end{cases}
$$

Then

(i) $f$ is a Prešić-Reich contraction with $\alpha_{1}=\alpha_{2}=$ $1 / 5, \beta_{1}=\beta_{2}=\beta_{3}=1 / 11$;

(ii) $f$ is not a Prešić contraction;

(iii) $f$ is not a Prešić-Kannan contraction.

Proof. (i) Note that for $x_{1}, x_{2}, x_{3} \in[0,1)$ with $x_{1} \leq x_{2} \leq x_{3}$,

$$
\begin{aligned}
d(f & \left.\left(x_{1}, x_{2}\right), f\left(x_{2}, x_{3}\right)\right) \\
& =d\left(\frac{x_{1}+x_{2}}{5}, \frac{x_{2}+x_{3}}{5}\right)=\frac{x_{3}-x_{1}}{5} \\
& =\frac{1}{5}\left[\left(x_{2}-x_{1}\right)+\left(x_{3}-x_{2}\right)\right] \\
& =\frac{1}{5}\left[d\left(x_{1}, x_{2}\right)+d\left(x_{2}, x_{3}\right)\right] \\
& =\frac{1}{5} \sum_{i=1}^{2} d\left(x_{i}, x_{i+1}\right) .
\end{aligned}
$$

Therefore conditions (11) and (12) are satisfied for $\alpha_{1}=\alpha_{2}=$ $1 / 5$ and $\beta_{1}, \beta_{2}, \beta_{3}$ with $\beta_{1}+\beta_{2}+\beta_{3} \in[0,3 / 10)$.

If any one of $x_{1}, x_{2}, x_{3}$ is 1 then proof is similar. If any two of $x_{1}, x_{2}, x_{3}$ are 1 , for example, if $x_{1} \in[0,1)$ and $x_{2}=x_{3}=1$, then

$$
\begin{aligned}
d\left(f\left(x_{1}, x_{2}\right), f\left(x_{2}, x_{3}\right)\right) & \\
= & d\left(f\left(x_{1}, 1\right), f(1,1)\right)=d\left(\frac{x_{1}+1}{5}, \frac{1}{5}\right) \\
& =\frac{x_{1}+1}{5}-\frac{1}{5}=\frac{x_{1}}{5} \\
\frac{1}{11} \sum_{i=1}^{3} d\left(x_{i}, f\left(x_{i}, x_{i}\right)\right) & \\
= & \frac{1}{11}\left[d\left(x_{1}, f\left(x_{1}, x_{1}\right)\right)+d\left(x_{2}, f\left(x_{2}, x_{2}\right)\right)\right. \\
& +\frac{1}{11}\left[\frac{3 x_{1}}{5}+\frac{4}{5}+\frac{4}{5}\right]=\frac{1}{55}\left[3 x_{1}+8\right] .
\end{aligned}
$$

As $x_{1} \in[0,1)$, so conditions (11) and (12) are satisfied for $\beta_{1}=$ $\beta_{2}=\beta_{3}=1 / 11$ and $\alpha_{1}, \alpha_{2}$ with $\alpha_{1}+\alpha_{2} \in[0,5 / 11)$.

Similarly in all possible cases conditions (11) and (12) are satisfied with $\alpha_{1}=\alpha_{2}=1 / 5, \beta_{1}=\beta_{2}=\beta_{3}=$ $1 / 11$. Therefore $f$ is a Prešić-Reich contraction. All other conditions of Corollary 7 are satisfied and 0 is the unique fixed point of $f$. (ii) Note that for $x_{1}=9 / 10$ and $x_{2}=x_{3}=1$

$$
\begin{aligned}
& d\left(f\left(x_{1}, x_{2}\right), f\left(x_{2}, x_{3}\right)\right)=d\left(\frac{19}{50}, \frac{1}{5}\right)=\frac{9}{50} \\
& \sum_{i=1}^{2} \alpha_{i} d\left(x_{i}, x_{i+1}\right)=\alpha_{1} d\left(x_{1}, x_{2}\right)+\alpha_{2} d\left(x_{2}, x_{3}\right) \\
&=\alpha_{1} d\left(\frac{9}{10}, 1\right)+\alpha_{2} d(1,1)=\frac{1}{10} \alpha_{1} .
\end{aligned}
$$

Therefore, we cannot find nonnegative constants $\alpha_{1}, \alpha_{2}$ such that condition (7) is satisfied with $\alpha_{1}+\alpha_{2}<1$. So $f$ is not a Prešić contraction.

(iii) Again for $x_{1}=x_{2}=0, x_{3}=1$

$$
\begin{gathered}
d\left(f\left(x_{1}, x_{2}\right), f\left(x_{2}, x_{3}\right)\right)=d\left(0, \frac{1}{5}\right)=\frac{1}{5} \\
\beta \sum_{i=1}^{3} d\left(x_{i}, f\left(x_{i}, x_{i}\right)\right) \\
=\beta\left[d\left(x_{1}, f\left(x_{1}, x_{1}\right)\right)+d\left(x_{2}, f\left(x_{2}, x_{2}\right)\right)\right. \\
\left.\quad+d\left(x_{3}, f\left(x_{3}, x_{3}\right)\right)\right] \\
=\beta\left[d(0,0)+d(0,0)+d\left(1, \frac{1}{5}\right)\right]=\frac{4}{5} \beta .
\end{gathered}
$$

Therefore, we cannot find nonnegative constant $\beta$ such that conditions (9) and (10) are satisfied. So $f$ is not a PrešićKannan contraction.

Remark 11. In the above example, we cannot apply the result of Prešić [7, 8] and Păcurar [11] to conclude the existence of fixed point of $f$. But Corollary 7 is applicable which insures the existence of unique fixed point of $f$.

Example 12. Let $X=[0,1]$ with usual metric. For $k=2$, define $f: X^{2} \rightarrow X$ by

$$
f(x, y)= \begin{cases}\frac{4}{15}, & \text { if } x=y=1 \\ 0, & \text { otherwise }\end{cases}
$$

Then

(i) $f$ is a Prešić-Chatterjea contraction with $\gamma \in$ $[1 / 13,1 / 12)$;

(ii) $f$ is not a Prešić contraction;

(iii) $f$ is not a Prešić-Kannan contraction.

Proof. (i) Note that if $x_{1}, x_{2}, x_{3} \in[0,1)$ or any one of $x_{1}, x_{2}, x_{3}$ is 1 , then conditions (17) and (18) are satisfied trivially. 
If any two of $x_{1}, x_{2}, x_{3}$ are 1 , for example, if $x_{1} \in[0,1)$, $x_{2}=x_{3}=1$, then

$$
\begin{gathered}
d\left(f\left(x_{1}, x_{2}\right), f\left(x_{2}, x_{3}\right)\right) \\
=d\left(f\left(x_{1}, 1\right), f(1,1)\right) \\
=d\left(0, \frac{4}{15}\right)=\frac{4}{15} \\
\gamma \sum_{i=1, i \neq j}^{3} \sum_{j=1}^{3} d\left(x_{i}, f\left(x_{j}, x_{j}\right)\right) \\
=\gamma\left[d\left(x_{1}, \frac{4}{15}\right)+d\left(x_{1}, \frac{4}{15}\right)\right. \\
\quad+d(1,0)+d\left(1, \frac{4}{15}\right) \\
\left.\quad+d(1,0)+d\left(1, \frac{4}{15}\right)\right] \\
=\gamma\left[2\left|x_{1}-\frac{4}{15}\right|+2+\frac{22}{15}\right] \\
\leq \gamma \frac{52}{15} . \\
=\gamma\left[2\left|x_{1}-\frac{4}{15}\right|+\frac{52}{15}\right]
\end{gathered}
$$

Therefore conditions (13) and (14) are satisfied with $\gamma \in$ $[1 / 13,1 / 12)$. Also all other conditions of Corollary 9 are satisfied and $f$ has a unique fixed point 0 .

(ii) For $x_{1}=9 / 10, x_{2}=1, x_{2}=1$, we have

$$
\begin{aligned}
& d\left(f\left(x_{1}, x_{2}\right), f\left(x_{2}, x_{3}\right)\right) \\
& \quad=d\left(f\left(\frac{9}{10}, 1\right), f(1,1)\right)=d\left(0, \frac{4}{15}\right)=\frac{4}{15} \\
& \sum_{i=1}^{2} \alpha_{i} d\left(x_{i}, x_{i+1}\right) \\
& =\alpha_{1} d\left(x_{1}, x_{2}\right)+\alpha_{2} d\left(x_{2}, x_{3}\right)=\alpha_{1} \frac{1}{10} .
\end{aligned}
$$

Therefore we cannot find nonnegative constants $\alpha_{1}, \alpha_{2}$ such that condition (7) is satisfied with $\alpha_{1}+\alpha_{2}<1$. So $f$ is not a Prešić contraction.

(iii) For $x_{1}=0, x_{2}=x_{3}=1$, we have

$$
\begin{aligned}
& d\left(f\left(x_{1}, x_{2}\right), f\left(x_{2}, x_{3}\right)\right) \\
& =d(f(0,1), f(1,1))=d\left(0, \frac{4}{15}\right)=\frac{4}{15} \\
& \beta \sum_{i=1}^{3} d\left(x_{i}, f\left(x_{i}, x_{i}\right)\right) \\
& =\beta\left[d\left(x_{1}, f\left(x_{1}, x_{1}\right)\right)+d\left(x_{2}, f\left(x_{2}, x_{2}\right)\right)\right. \\
& \left.+d\left(x_{3}, f\left(x_{3}, x_{3}\right)\right)\right]=\beta \frac{22}{15} .
\end{aligned}
$$

Therefore we cannot find nonnegative constant $\beta$ such that conditions (9) and (10) are satisfied. So $f$ is not a PrešićKannan contraction.

Remark 13. In the above example, we cannot apply the result of Prešić [7, 8] and Păcurar [11] to conclude the existence of fixed point of $f$. But Corollary 9 is applicable which insures the existence of unique fixed point of $f$.

The following theorem is a consequence of Theorem 4 and the recent result of Aydi et al. [20].

Theorem 14. Let $(X, d)$ be any complete metric space and $k a$ positive integer. Let $f: X^{k} \rightarrow X$ and $T: X \rightarrow X$ be two mappings such that the following condition holds:

$$
\begin{aligned}
d(T f & \left.\left(x_{1}, x_{2}, \ldots, x_{k}\right), T f\left(x_{2}, x_{3}, \ldots, x_{k+1}\right)\right) \\
\leq & \sum_{i=1}^{k} \alpha_{i} d\left(T x_{i}, T x_{i+1}\right) \\
& +\sum_{i=1}^{k+1} \sum_{j=1}^{k+1} \beta_{i, j} d\left(T x_{i}, T f\left(x_{j}, x_{j}, \ldots, x_{j}\right)\right)
\end{aligned}
$$

for all $x_{1}, x_{2}, \ldots, x_{k}, x_{k+1} \in X$, where $\alpha_{i}, \beta_{i, j}$ are nonnegative constants such that

$$
\sum_{i=1}^{k} \alpha_{i}+k \sum_{i=1}^{k+1} \sum_{j=1}^{k+1} \beta_{i, j}<1
$$

and $T$ is continuous, injective, and sequentially convergent. Then $f$ has a unique fixed point in $X$.

Proof. Define a mapping $\rho: X \times X \rightarrow[0, \infty)$ by

$$
\rho(x, y)=d(T x, T y) \quad \forall x, y \in X .
$$

Then $(X, \rho)$ is a complete metric space (see [20]). Note that condition (46) reduces to the condition (17); that is, mapping $f$ reduces to Prešić-Hardy-Rogers contraction with respect to metric $\rho$. So the rest of the proof followed Theorem 4 .

\section{Acknowledgment}

The first author is thankful to Mr. Rajpal Tomar for his help in typing the manuscript.

\section{References}

[1] R. Kannan, "Some results on fixed points," Bulletin of the Calcutta Mathematical Society, vol. 60, pp. 71-76, 1968.

[2] R. Kannan, "Some results on fixed points. II," The American Mathematical Monthly, vol. 76, pp. 405-408, 1969.

[3] S. Reich, "Some remarks concerning contraction mappings," Canadian Mathematical Bulletin, vol. 14, pp. 121-124, 1971.

[4] S. K. Chatterjea, "Fixed-point theorems," Comptes Rendus de l'Académie Bulgare des Sciences, vol. 25, pp. 727-730, 1972.

[5] L. B. Ćirić, "Generalized contractions and fixed-point theorems," Publications de l'Institut Mathématique, vol. 12, no. 26, pp. 19-26, 1971. 
[6] G. E. Hardy and T. D. Rogers, "A generalization of a fixed point theorem of Reich," Canadian Mathematical Bulletin, vol. 16, pp. 201-206, 1973.

[7] S. B. Prešić, "Sur une classe d'inéquations aux différences finies et sur la convergence de certaines suites," Publications de l'Institut Mathématique, vol. 5, no. 19, pp. 75-78, 1965.

[8] S. B. Prešić, "Sur la convergence des suites," Comptes Rendus de l'Académie des Sciences, vol. 260, pp. 3828-3830, 1965.

[9] L. B. Ćirić and S. B. Prešić, "On Prešić type generalization of the Banach contraction mapping principle," Acta Mathematica Universitatis Comenianae, vol. 76, no. 2, pp. 143-147, 2007.

[10] M. Pãcurar, "A multi-step iterative method for approximating common fixed points of Prešić-Rus type operators on metric spaces," Studia Universitatis Babes-Bolyai, Mathematica, vol. 55, no. 1, p. 149, 2010.

[11] M. Păcurar, "Approximating common fixed points of PresićKannan type operators by a multi-step iterative method," Analele Stiintifice ale Universitatii Ovidius Constanta, Seria Matematica, vol. 17, no. 1, pp. 153-168, 2009.

[12] M. Păcurar, "Common fixed points for almost Presić type operators," Carpathian Journal of Mathematics, vol. 28, no. 1, pp. 117-126, 2012.

[13] M. S. Khan, M. Berzig, and B. Samet, "Some convergence results for iterative sequences of Prešić type and applications," Advances in Difference Equations, vol. 2012, article 38, 2012.

[14] R. George, K. P. Reshma, and R. Rajagopalan, "A generalised fixed point theorem of Presic type in cone metric spaces and application to Markov process," Fixed Point Theory and Applications, vol. 2011, article 85, 2011.

[15] S. Shukla, R. Sen, and S. Radenović, "Set-valued Prešić type contraction in metric spaces," Analele Stiintifice ale Universitatii. In press.

[16] S. Shukla and R. Sen, "Set-valued Prešić-Reich type mappings in metric spaces," Revista de la Real Academia de Ciencias Exactas, Fisicas y Naturales A, 2012.

[17] S. K. Malhotra, S. Shukla, and R. Sen, "A generalization of Banach contraction principle in ordered cone metric spaces," Journal of Advanced Mathematical Studies, vol. 5, no. 2, pp. 5967, 2012.

[18] Y.-Z. Chen, "A Prešić type contractive condition and its applications," Nonlinear Analysis, vol. 71, no. 12, pp. e2012-e2017, 2009.

[19] B. E. Rhoades, "A comparison of various definitions of contractive mappings," Transactions of the American Mathematical Society, vol. 226, pp. 257-290, 1977.

[20] H. Aydi, E. Karapınar, and B. Samet, "Remarks on some recent fixed point theorems," Fixed Point Theory and Applications, vol. 2012, article 76, 2012. 


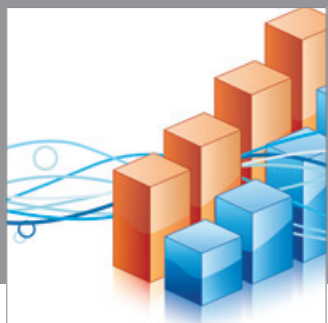

Advances in

Operations Research

mansans

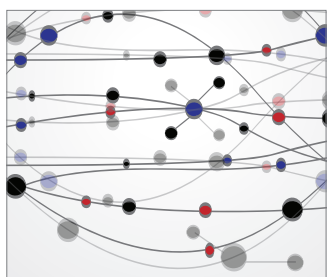

The Scientific World Journal
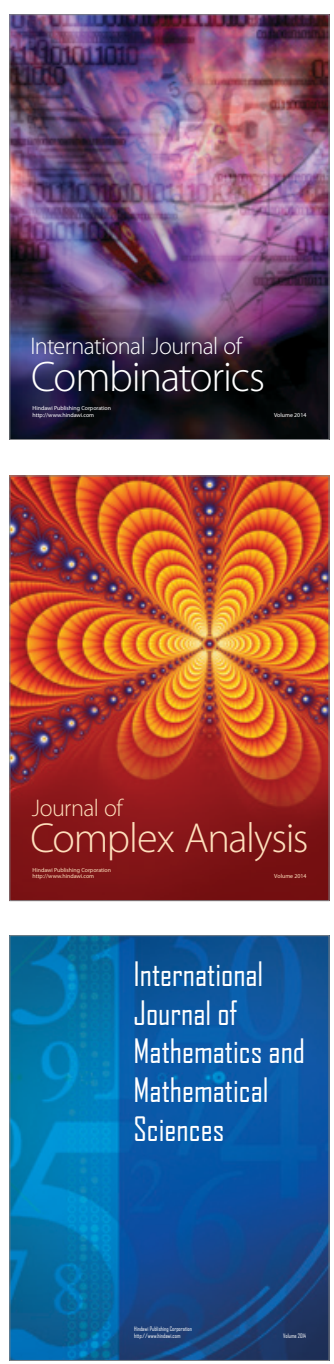
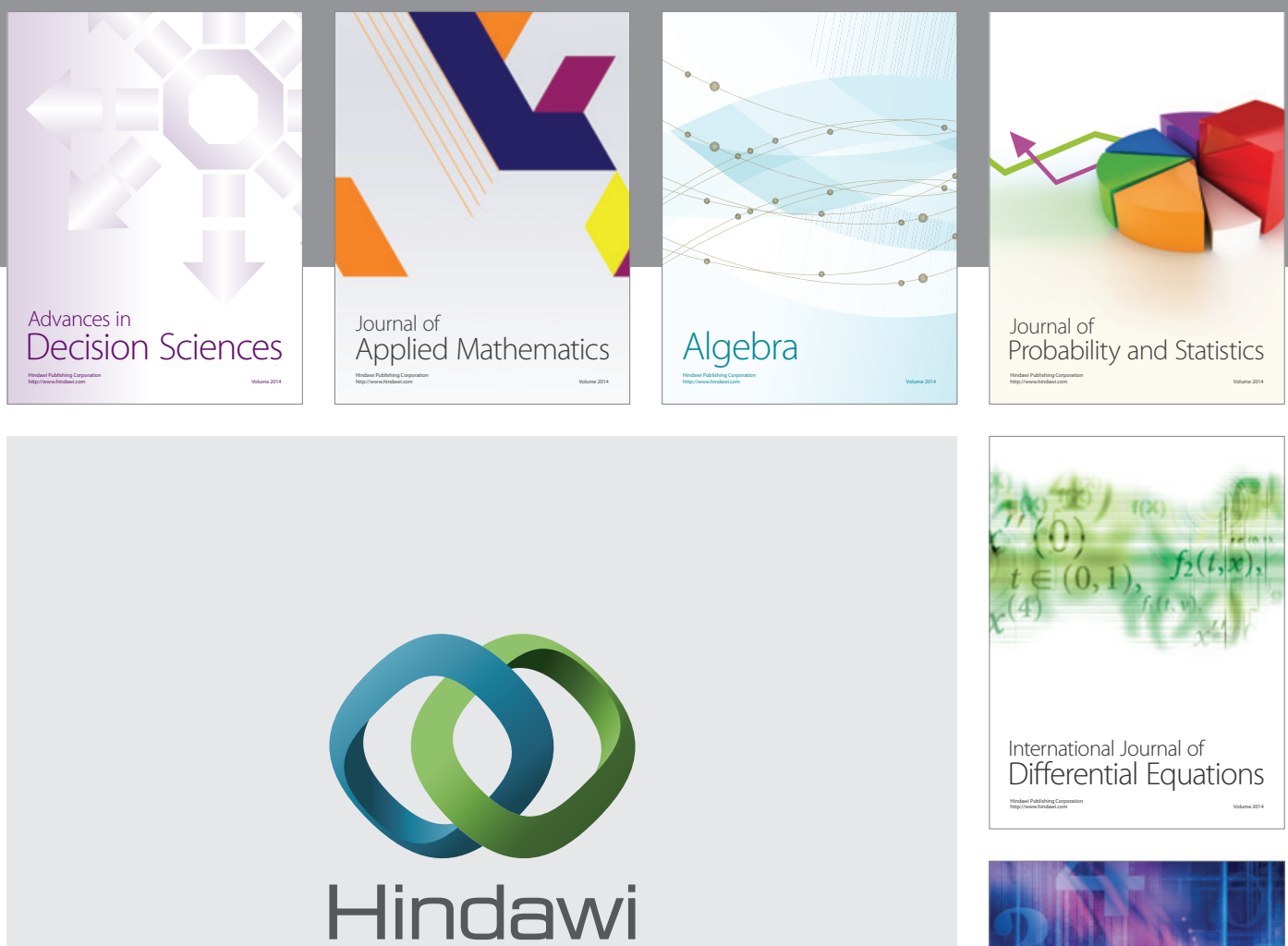

Submit your manuscripts at http://www.hindawi.com
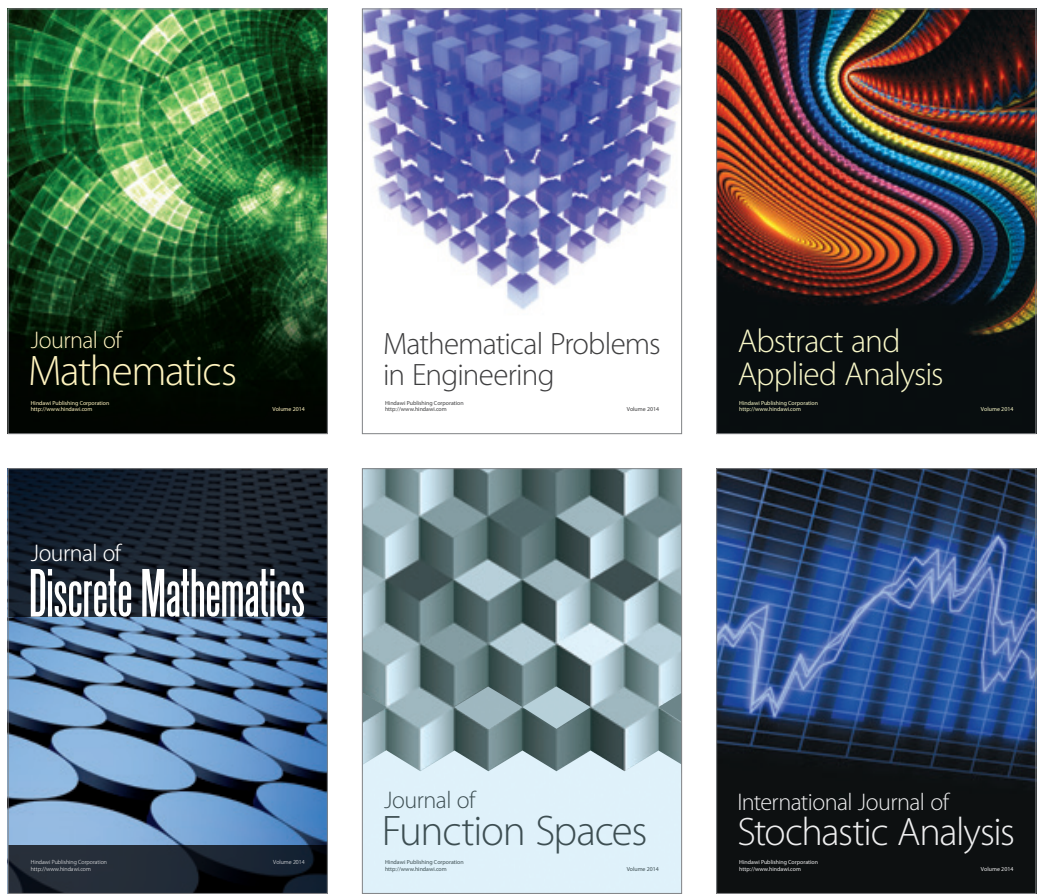

Journal of

Function Spaces

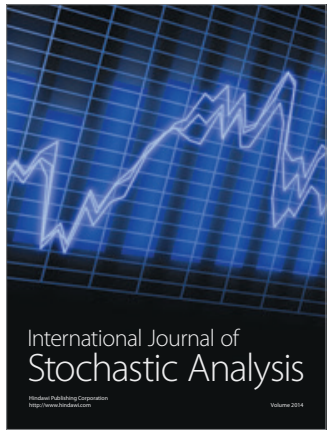

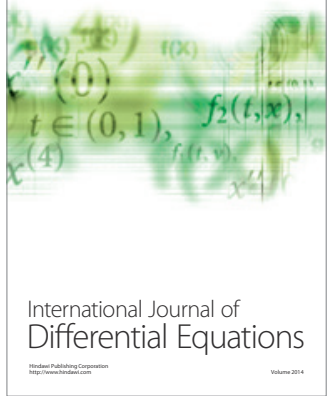
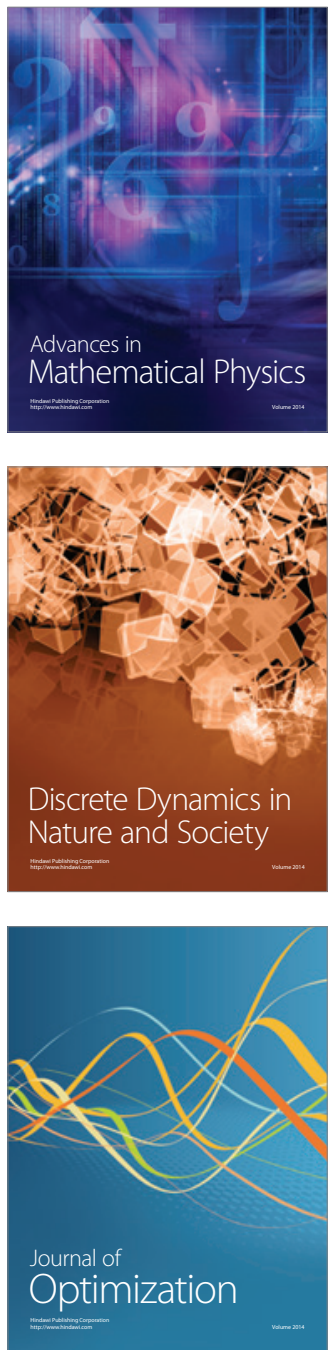